\title{
Future Prospects for SEM-based Defect Analysis using Fast Electrons
}

\author{
Y.N. Picard*, R.J. Kamaladasa*, N. Kumar**, C. Trager-Cowan**, W. Jiang*, M. Skowronski*, \\ P.A. Salvador*, H. Behmemburg***, and C. Giesen***, A.P. Day****, G. England***** \\ * Dept. of Materials Science and Engr., Carnegie Mellon University, Pittsburgh, PA 15213, USA \\ ** Dept of Physics, SUPA, University of Strathclyde, G4 ONG Glasgow, Scotland, UK \\ ***AIXTRON AG, Kaiserstr. 98, 52134, Herzogenrath, Germany \\ ****A Aunt Daisy Scientific Ltd, Dixton Rd, Monmouth, NP25 3PP Gwent, UK \\ $* * * * *$ K.E. Developments Ltd, CB23 2RL Cambridge, UK
}

"Fast electrons" or backscattered electrons (BSEs) have long been utilized inside the conventional SEM for enhanced topographic or Z-contrast imaging. Additionally, fast electrons can be utilized for direct structural analysis of crystalline materials via electron backscatter diffraction (EBSD). Fast electrons thus provide a number of avenues for imaging and analysis that help make SEM arguably the most versatile instrument for materials analysis. However, TEM offers one important capability generally lacking for SEM: the ability to employ diffraction contrast towards direct imaging and identification of individual defects in materials.

Material defects continue to be a major issue in many technological realms. One avenue where fast electrons can add versatility to the conventional SEM towards defect analysis is electron channeling. Electron channeling is the phenomena where the BSE yield is a strong function of the incoming electron beam trajectory relative to a crystalline sample orientation [1]. Using fast electrons for electron channeling contrast imaging (ECCI) has long stood as a possible means for direct defect analysis of materials inside an SEM. However, channeling has historically not seen wide-spread use largely due to limitations in electron source brightness and BSE detector efficiency. But with continued advances in SEM electro-optics, electron sources, and solid state detectors, recent electron channeling work has resolved individual defects using fully commercialized equipment $[2,3]$.

In this talk, various examples are presented where fast electrons are employed for direct defect imaging and analysis of single-crystalline materials. Defects in $\mathrm{GaN}$ films, $\mathrm{SrTiO}_{3}$ substrates, and multilayer III-nitride devices are imaged via ECCI using fully commercial SEMs and BSE detectors. Evidence for identifying defect type based on the nature of contrast feature profiles is described. Future prospects for continued application of fast electrons towards defect and structural analysis of materials surfaces will be discussed. Avenues will be addressed for future modification of SEM instruments and BSE detectors in order to extend TEM-like capabilities to the ever more versatile SEM via fast electron imaging.

\section{References}

[1] D.G. Coates, Phil. Mag. 16 (1967) 1179.

[2] C. Trager-Cowan et. al., Phys. Rev. B. 75 (2007) 085301.

[3] Y. N. Picard et. al., Scripta Mater. 61 (2009) 773. 

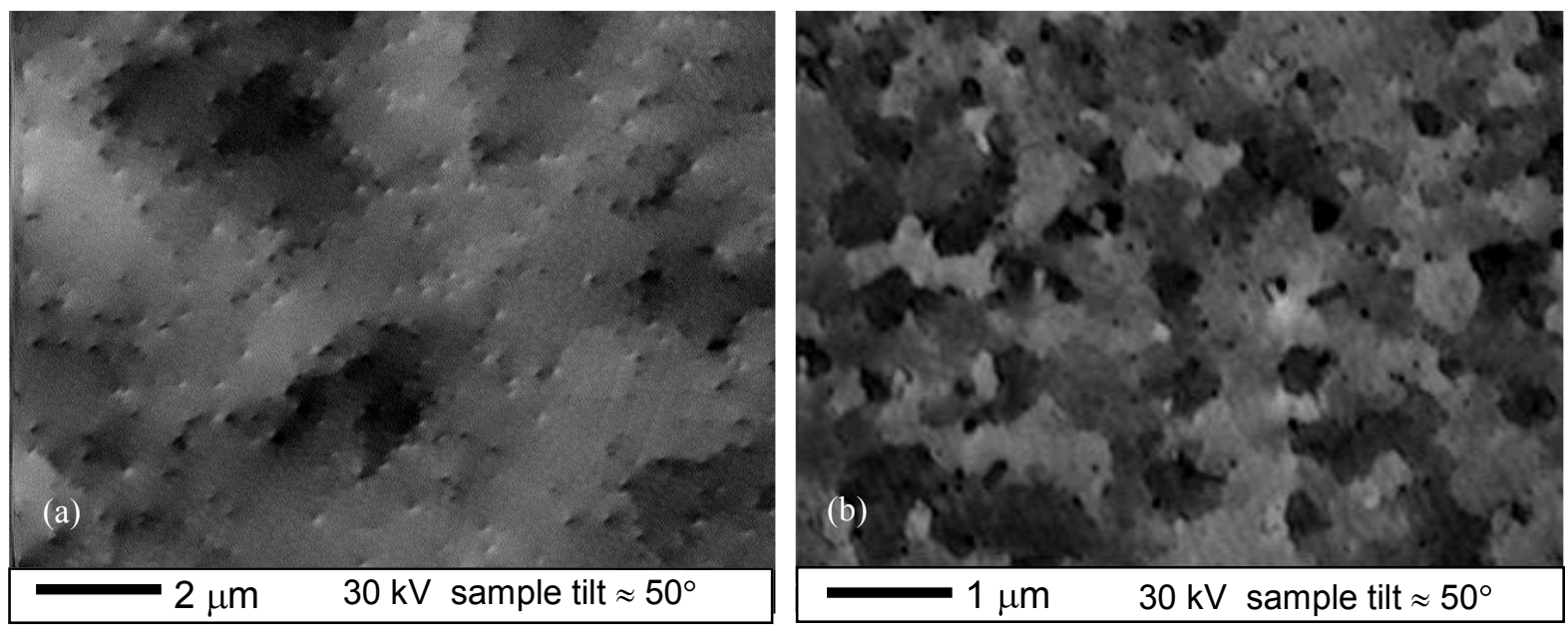

FIG. 1. ECCI micrographs of (a) an $\operatorname{In}_{0.14} \mathrm{Al}_{0.86} \mathrm{~N}(16 \mathrm{~nm}) / \mathrm{AlN}(2.5 \mathrm{~nm}) / \mathrm{GaN}(3 \mu \mathrm{m}) / \mathrm{Al}_{2} \mathrm{O}_{3}$ heterostructure and (b) an $\operatorname{In}_{0.14} \mathrm{Al}_{0.86} \mathrm{~N}(33 \mathrm{~nm}) / \mathrm{AlN}(1 \mathrm{~nm}) / \mathrm{GaN}(3 \mu \mathrm{m}) / \mathrm{Al}_{2} \mathrm{O}_{3}$ heterostructure. The $16 \mathrm{~nm}$ InAlN layer is single-crystalline with a dislocation density of $\sim 3 \times 10^{8} \mathrm{~cm}^{-2}$ while the $33 \mathrm{~nm}$ layer is polycrystalline.

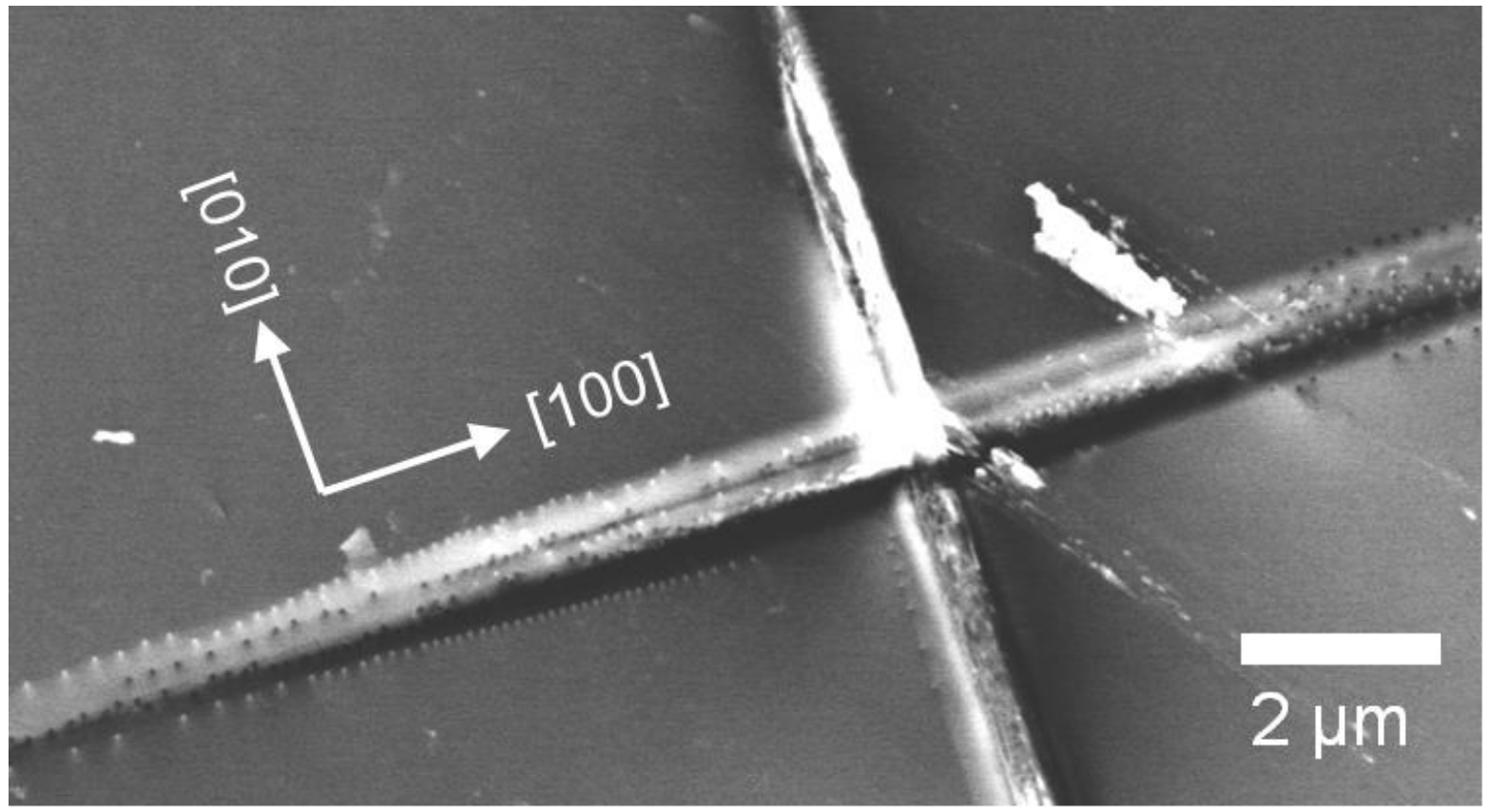

FIG. 2. ECCI micrograph of prismatic slip bands bounded by dislocation arrays (lines of spots) in (001) $\mathrm{Nb}$-doped $\mathrm{SrTiO}_{3}$ with $\mathbf{g}=100$. 